\title{
Ocorrência de agentes infecciosos em torneiras dos banheiros de uma instituição de ensino superior
}

\author{
Occurrence of infectious agents on taps of toilets of an institution of higher education \\ Helena Maria do Carmo Oliveira Filha ${ }^{1}$, Josefa Rejane Gomes Rocha ${ }^{1}$, Thiago José Matos-Rocha ${ }^{2}$, \\ Emanuelle Cavalcante Pimentel ${ }^{3}$, Samara Almeida de Souza Griz ${ }^{3}$, Valéria Cristina de Melo Lopes ${ }^{4}$, \\ Mônica Meira Leite Rodrigues ${ }^{3}$
}

\section{Resumo}

Objetivo: O trabalho teve como objetivo avaliar a ocorrência de bactérias, nas superfícies de contato com as mãos, das torneiras dos banheiros de uma instituição de ensino superior, a partir da realização de cultura das mesmas. Material e Métodos: A coleta foi realizada com swabs descartáveis estéreis, umedecidos em solução salina estéril no momento da coleta. Para identificação dos agentes bacterianos, cada amostra foi semeada em uma placa de petri descartável contendo meio de cultura Ágar sangue e outra contendo meio de cultura Ágar MacConkey para verificar o crescimento bacteriano. Resultados: Das amostras analisadas $7(18,9 \%)$ não apresentaram crescimento bacteriano, $30(81,1 \%)$ apresentaram resultado positivo sendo 18 (48,6\%) Staphylococcus coagulase negativa, 2 (5,4\%), Staphylococcus aureus, 1 (2,7\%) Pseudomonas aeruginosa, 6 (16,3\%) Enterobactérias e Staphylococccus coagulase negativa, 2 (5,4\%) Enterobactérias, 1 (2,7\%) Pseudomonas e Staphylococcus coagulase negativa. Frente à análise dos resultados, conclui-se que as superfícies das torneiras que os usuários entram em contato, apresentaram contaminação por bactérias. Conclusão: O fato pode ser devido a um protocolo ineficaz de limpeza das mesmas, falta de informação da população sobre a maneira correta de lavagem das mãos e utilização das torneiras

1. Graduada em Farmácia pelo Centro Universitário CESMAC

2. Professor de Parasitologia Humana da Universidade Estadual de Ciências da Saúde de Alagoas. Coordenador da Especialização de Análises Microbiológicas e Parasitológicas, Farmácia Hospitalar e Citologia Clínica no Centro Universitário CESMAC

3. Professora Titular do Curso de Farmácia do Centro Universitário CESMAC

4. Coordenadora do Curso de Graduação em Farmácia e Pós-Graduação em Análises Clínicas do Centro Universitário CESMAC Trabalho realizado: Centro Universitário CESMAC

Endereço para Correspondência: Thiago José Matos Rocha. Rua Cônego Machado, 918. Bairro: Farol - 57051-160 Maceió - Alagoas - Brasil. Tel.: +55 (82) 3215-5137. E-mail: thy_rocha@hotmail.com após o uso dos banheiros, bem como as torneiras serem de uso manual.

Descritores: Bactérias, Infecções bacterianas, Vigilância epidemiológica

\begin{abstract}
Objective: The work aimed to evaluate the occurrence of bacteria, contact surfaces with your hands, the taps of the bathrooms of a higher education institution, from the realization of the same culture. Material and methods: The collection was performed with disposable sterile swab, moistened in sterile saline solution at the time of collection. For identification of bacterial agents, each sample was seeded in a petri dish containing Agar culture medium disposable blood and another containing MacConkey agar culture medium to check for bacterial growth. Results: The samples analysed $7(18.9 \%)$ showed no bacterial growth, $30(81.1 \%)$ showed positive result being 18 (48.6\%) Staphylococcus coagulase negative, 2 (5.4\%), Staphylococcus aureus, 1 (2.7\%) Pseudomonas aeruginosa, 6 (16.3\%) Enterobacteria and Staphylococccus coagulase, 2 (5.4\%) Enterobacteria, $1(2.7 \%)$ Pseudomonas and Staphylococcus coagulase. Front of the analysis of the results, it is concluded that the surfaces of the faucets that users come into contact, showed contamination by bacteria. Conclusion: The fact may be due to an ineffective cleaning Protocol, lack of information of the population about the proper way to hand washing and use of taps after using the toilets, as well as the taps are in the hand.
\end{abstract}

Key words: Bacteria, Bacterial infections, Epidemiological Surveillance

\section{Introdução}

As bactérias são estruturas unicelulares, microscópicas encontradas isoladamente ou em colônias, na água no ar e em superfícies de objetos, podendo estas serem patogênicas, sendo assim nocivas ao homem ${ }^{(1)}$. 
A lavagem das mãos é um procedimento simples e importante na prevenção da infecção. Quando realizada corretamente remove os microrganismos evitando a propagação de doenças ${ }^{(2)}$.

A microbiota das mãos é constituída por bactérias residentes e transitórias. A microbiota residente coloniza as camadas mais profundas da epiderme, sendo mais difícil de ser removida e normalmente não está associada a infecções cruzadas. É composta pelos Staphylococcus coagulase negativa (SCoN), Micrococcus sp. e Corinebactérias, eles se multiplicam e se mantêm em equilíbrio com as defesas do hospedeiro ${ }^{(3)}$.

A microbiota transitória coloniza a camada superior da pele, sendo mais fácil a sua remoção pela lavagem das mãos, é proveniente de fontes externas através de contato com pessoas ou superfícies contaminadas. Os componentes mais comuns desta microbiota são bactérias gram negativas, como: Enterobactérias e Pseudomonas. Por serem facilmente removidas da pele, as bactérias que compõem essa microbiota também se espalham com mais facilidade pelo contato e são eliminados com mais facilidade ${ }^{(3)}$.

Os estafilococos são bactérias pertencentes à família Micrococcaceae, são cocos gram positivos que formam cachos irregulares, aos pares, isolados, ou em cadeias curtas. São classificados em dois grupos: coagulase positiva, cujos principais representantes são Staphylococcus aureus e SCoN, onde os mais frequentes associados a infecções humanas são $S$. epidermides, $S$. haemolyticus, S. warneri, S. saprophyticus e S. lugdunen$\operatorname{sis}^{(4)}$.

O S. aureus é o mais importante patógeno humano, são bactérias gram positivas, imóveis, não formadores de esporos muito resistentes às adversidades ambientais, são anaeróbios facultativos, podem expressar genes que sintetizam fatores de virulência que além de facilitar a aderência ao tecido, diminuem as defesas do organismo. Podem causar doenças desde intoxicações alimentares, infecções cutâneas de pouca importância, até infecções hospitalares graves, principalmente da corrente sanguínea. Essas infecções podem acometer pessoas de todas as idades, em especial nos extremos de idade ${ }^{(5)}$.

SCoN são encontrados na pele e mucosas dos seres humanos. A incidência a estes microrganismos vem aumentando e passaram a ser reconhecidos como agentes oportunistas causadores de infecções urinárias, infecções associadas a dispositivos permanentes, bacteremias em hospedeiros comprometidos, endocardites de válvulas cardíacas, osteomielite e endoftalmite pós-cirúrgica ${ }^{(5)}$.

As enterobactérias predominam a microbiota intestinal humana, e são comumente associadas tanto a infecções na comunidade como a infecções nosocomiais. Várias espécies podem causar infecções intestinais e extra-intestinais, estas últimas podem ser localizadas ou sistêmicas. As infecções localizadas mais frequentes são as das vias urinárias, dos pulmões, da pele e do tecido celular subcutâneo ${ }^{(6)}$.

Pseudomonas aeruginosa, é uma bactéria Gram negativa, que se apresenta sob a forma de bastonetes isolados ou aos pares, é o maior agente patogênico do seu grupo. Possuem necessidades nutricionais mínimas, sobrevivendo em uma grande variedade de ambientes como água, solo, ambientes úmidos, plantas e amostras clinicas. É uma bactéria fácil de ser reconhecida em cultura, devido às características de suas colônias, formação de pigmento e seu odor típico ${ }^{(6)}$.

A bactéria P. aeruginosa é umpatógeno oportunista, invasivo e toxigênico que pode colonizar vários tecidos. Em ambientes hospitalares, esta bactéria torna-se um importante agente infeccioso, principalmente em pacientes predispostos, que apresentam quebra de barreiras físicas e imunossupressão como em portadores de infecções urinárias associadas ao uso de cateteres e em pacientes vítimas de queimaduras ${ }^{(7)}$.

De forma geral, como foi dito anteriormente, diferentes espécies de bactérias podem causam infecções de importância médica em humanos. O grupo de patógenos, no entanto, que possui maior destaque são as bactérias que constituem a flora humana e que normalmente não trazem risco a indivíduos saudáveis, devido à sua baixa virulência, mas podem causar infecção em indivíduos imunocomprometidos, sendo denominadas de bactérias oportunistas ${ }^{(8)}$.

A exposição de um indivíduo frente a bactérias em condições normais, ou seja, na presença de um sistema imunológico competente, não causam nenhum tipo de dano, porém em indivíduo que apresente um sistema imunológico debilitado, estas bactérias podem desencadear infecções graves devido à quebra de equilíbrio entre a microbiota normal e o hospedeiro ${ }^{(9)}$.

A falta de limpeza adequada nas superfícies das torneiras ou objetos que estão em contato com um grande número de frequentadores pode possibilitar o aumento da contaminação por contato com resíduos de fezes, urina ou secreções genitais contendo bactérias causadoras de infecções e outros microrganismos ${ }^{(9)}$.

A área mais suja em um banheiro não é o vaso sanitário ou a maçaneta, é a torneira. As bactérias ficam na torneira porque as pessoas tocam essas superfícies logo após usar o banheiro e recontaminando-a ao fechar. Como essa é uma área úmida, as bactérias podem sobreviver em condições muito adversas e permanecer viáveis por vários meses ${ }^{(10)}$.

Nesse sentido, muitas bactérias são transmitidas de pessoa para pessoa, através de superfícies de equipamentos de uso comum, elas podem atingir o organismo através de feridas abertas ou por contato direto com mucosas. A contaminação entre pessoas ou 
de uma pessoa por um objeto contaminado é denominado contaminação cruzada ${ }^{(11)}$.

Por isso, os procedimentos básicos de descontaminação são de fundamental importância para a prevenção e disseminação de doenças. A limpeza consiste no processo de remoção da sujidade o que inclui a remoção dos microrganismos nela contidos e da matéria orgânica que favorece a sobrevivência e proliferação dos mesmos ${ }^{(12)}$.

A justificativa de realizar o estudo é embasada na importância de mostrar possíveis reservatórios ambientais de contaminação microbiana em ambiente de amplo uso, e de contribuir com informações que possam ser usadas para basear ações no sentido de minorizar o problema. Este estudo é de grande importância, para que a comunidade acadêmica da instituição esteja ciente da existência ou não de agentes microbianos que possam estar presentes nas torneiras utilizadas diariamente por estudantes e demais profissionais que fazem uso dos banheiros da instituição da pesquisa. Portanto, o trabalho teve como objetivo investigar a presença de bactérias em torneiras de banheiros em uma instituição de ensino superior de Maceió-AL.

\section{Material e métodos}

O trabalho trata-se de um estudo transversal de prevalência, realizado nos banheiros do Complexo Educacional Professor Eduardo Almeida do Centro Universitário Cesmac (Campus I), onde foram coletadas amostras nas superfícies das torneiras dos banheiros.

Foram incluídas nesse estudo as torneiras de todos os banheiros do campus I, este dispõe de 37 banheiros, com 75 torneiras localizadas nos quatro andares do Complexo Educacional: térreo, $1^{\circ}, 2^{\circ} \mathrm{e} 3^{\circ}$ andar, Laboratório de Farmacotécnica/Farmacognosia e Clínica de enfermagem (UDAE). Os banheiros são de livre acesso a acadêmicos, funcionários, professores e público em geral e alguns são reservados as coordenações, sala dos professores e secretaria. Por não haver padronização na quantidade das torneiras distribuídas nos banheiros, a amostragem foi realizada em uma única torneira de cada banheiro, escolhida aleatoriamente, totalizando 37 amostras.

Como procedimento para obtenção das amostras, todas as amostras biológicas foram coletadas no período vespertino após a higienização dos banheiros. A coleta foi realizada com swabs descartáveis estéreis, umedecidos em solução salina estéril no momento da coleta. O swab foi friccionado na superfície superior da torneira (local de contato com as mãos dos usuários), em seguida inserido em tubo de ensaio tamponado estéril contendo meio de transporte stuart e identificado de acordo com o ambiente investigado. Após a coleta das amostras dos banheiros, as mesmas foram levadas imediatamente ao laboratório de pesquisa acadêmica do Complexo Educacional para inoculação.

Para identificação dos agentes bacterianos, cada amostra foi semeada em uma placa de petri descartável contendo meio de cultura Ágar sangue e outra contendo meio de cultura Ágar MacConkey para verificar o crescimento bacteriano. $\mathrm{O}$ tipo de semeadura empregado foi o esgotamento por estrias para obtenção de colônias isoladas. Após o semeio as placas foram incubadas em estufa bacteriológica a $37^{\circ} \mathrm{C}$ por um período de 24 horas, para análise e identificação das culturas positivas. As placas que não apresentaram crescimento bacteriano foram incubadas por mais 24 horas $^{(13)}$

Após a verificação da morfologia das colônias, aquelas com características compatíveis com Staphylococcus foram submetidas à coloração pelo método de Gram e confirmação microscópica. Posteriormente, foram realizadas as provas da catalase, para diferenciação do gênero Staphylococcus de Streptococcus, e da DNAse, para diferenciação de $S$. aureus e $\mathrm{SCoN}^{(14)}$.

As colônias que apresentaram características semelhantes às bactérias gram negativas foram submetidas à coloração pelo método de Gram com confirmação microscópica e submetidas a testes complementares, por meio de provas bioquímicas, necessárias para a identificação das colônias suspeitas (TSI, SIM, Citrato de Simmons, Ureia, Lisina) ${ }^{(13)}$. Para diferenciação das espécies de Enterobacter e de Serratia foi necessário acrescentar Manitol, adonitol, malonato vermelho de metila (VM) e malonato Voges Proskauer $(V P)^{(1)}$.

\section{Resultados}

Foi coletado um total de 37 amostras das superfícies das torneiras existentes na instituição. Com relação às amostras analisadas $7(18,9 \%)$ não apresentaram crescimento bacteriano e $30(81,1 \%)$ apresentaram resultado positivo, sendo $18(48,6 \%)$ SCoN, $2(5,4 \%)$, S . aureus, 1 (2,7\%) P. aeruginosa, 6 (16,3\%) Enterobactérias e SCoN, 2 (5,4\%) Enterobactérias, 1 (2,7\%) P. aeruginosa e SCoN. Entre as amostras analisadas $26(100 \%)$, são do gênero Staphylococcus, sendo 24 (92,3\%), SCoN e $2(7,7 \%)$ S. aureus.

Entre bactérias da família Enterobacteriaceae foram isoladas $8(100 \%), 2(25 \%)$ Enterobacter aerogenes, 1 $(12,5 \%)$ Enterobacter sakazakii, 1 (12,5\%) Enterobacter gergoviae, 1 (12,5\%) Serratia liquifaciens, 1 (12,5\%) Serratia marcescens, 1 (12,5\%) Serratia rubidaea e 1 (12,5\%) Providencia stuartii.

Durante a coleta das amostras em nosso estudo foi observado que $100 \%$ das torneiras possuem acionamento manual. 


\section{Discussão}

No homem, as bactérias do gênero Staphylococcus podem ser encontradas no conduto nasal, trato digestório, nos olhos, na garganta e superfície da pele, sendo mais frequente nas mãos, braços, rosto e feridas ${ }^{(15-16)}$. Assim, essa bactéria pode contaminar superfícies direta ou indiretamente ${ }^{(16)}$.

Os SCoN foram os isolados de maior frequência nesse estudo. Estudo semelhante pesquisando Staphylococcus em superfícies e detecção de agentes contaminantes do ar em uma unidade de saúde foi observada em Belém-PA ${ }^{(10)}$.

A identificação das espécies de Staphylococcus sp. é de grande importância devido ao aumento do seu significado clínico, para tal é importante reconhecer possíveis reservatórios, a pesquisa realizada condiz com outros estudos. Um estudo realizado pesquisando a microbiota das mãos dos profissionais de saúde de um hospital particular de Itumbira-GO, demonstrou uma frequência de $44,5 \%$ de SCoN, seguido por $40 \%$ de S. aureus ${ }^{(11)}$.

A frequência encontrada nesse último estudo é semelhante à encontrada em nossa na pesquisa, porém, a percentagem diverge quando relacionado ao $S$. aureus, fato que se justifica quando observado a diferença entre os locais analisados. Em estudo sobre identificação de Staphylococcus em uma unidade de saúde, Belém do Pará, afirma que a presença de SCoN pode indicar condições higiênico-sanitárias insatisfatórias, fato que evidência a necessidade de capacitação e conscientização dos funcionários ${ }^{(17)}$.

Durante a coleta das amostras em nosso estudo foi observado que todas as torneiras possuem acionamento manual. Estudo semelhante ao nosso, afirma que a contaminação de torneiras para lavagem de mãos é preocupante, uma vez que imediatamente após o término da lavagem das mãos estas podem ser contaminadas novamente ao contato com a torneira. Isso reforça a necessidade da automatização das torneiras ${ }^{(12)}$.

Em outra pesquisa, analisando contaminantes de natureza fecal em torneiras de banheiros, os autores também afirmam e concordam que nossa teoria onde os modelos de torneiras que necessitam que os usuários coloquem as mãos ainda não lavadas em sua superfície para abrir e considerando que estas mãos estejam sujas ao tocar na superfície das torneiras, estas mãos podem voltar a ser contaminadas no momento do fechamento da torneira, por isso é recomenda ainda o uso de torneiras por foto célula ou com pedal ${ }^{(3)}$.

Alguns estudos demonstram que, é muito comum a presença das bactérias encontradas em nosso estudo, serem observados em outras superfícies, por exemplo, uma pesquisa sobre frequência de bactérias em com- putadores de uma instituição superior de Maceió-AL, os resultados demonstraram $97 \%$ de positividade para microrganismos bacterianos, corroborando com os resultados do nosso estudo quanto ao elevado numero de resultados positivos. Outra semelhante ao nosso trabalho foi visto com relação a maior prevalência de prevalência de SCoN. O autor sugere que possivelmente estas bactérias podem ser provenientes das mãos contaminadas de pessoas que utilizaram os banheiros da instituição ${ }^{(18)}$

Oculares de microscópios também podem ser veículos de contaminação pelas bactérias descritas em nosso estudo. Nessa pesquisa foram identificadas diversas bactérias, entre as quais coincidem com as encontradas neste estudo, bactérias Gram-positivas, $\mathrm{SCoN}$ e $S$. aureus. A presença de bactérias nas superfícies, assim como a microbiota normal não oferecem riscos ao homem, mas se houver diminuição da imunidade essas bactérias podem se tornar patogênicas ao hospedeiro ${ }^{(19)}$. Nesta pesquisa observou-se a presença de S. aureus, P. aeruginosa e E. aerogenes, bactérias essas também descritas em nosso estudo.

Embora fora do ambiente hospitalar a resistência de cepas Staphylococcus seja menos frequente, é de extrema importância a realização de testes laboratoriais para detecção de cepas de Staphylococcus resistentes à oxacilina (MRSA), entre as Pseudomonas cepas multirresistentes.

P. aeruginosa é um patógeno de grande interesse médico. Devido ao aumento de sua resistência à maioria dos antibióticos, é capaz de proliferar em ambientes úmidos, sendo mais frequente em equipamentos respiratórios e produtos de limpeza. Já que este patógeno é mais encontrado em ambiente hospitalar, sua ocorrência nas torneiras pode estar relacionada ao grande número de pessoas que circulam nos banheiros, vindas dos mais diversificados ambientes, podendo estar ocorrendo uma infecção cruzada através das mãos contaminadas $^{(20)}$.

Um estudo com detecção de enterobactérias em superfícies mostrou que a alta frequência de enterobactérias nas superfícies das torneiras se deve ao manejo manual destas, visto que estas bactérias pertencem a microbiota do trato gastrointestinal. Porém, podem causar infecções extraintestinais das mais diversas como: infecções das vias urinárias, dos pulmões, da pele e bacteremias ${ }^{(21)}$.

Ressalta-se, a partir desses resultados, a importância da lavagem das mãos sempre que houver sujidade aparente ou não. Existem muitos trabalhos sobre o isolamento de bactérias em superfícies hospitalares, porém dados especificamente sobre a contaminação nas superfícies das torneiras dos banheiros são escassos.

Numa pesquisa de bacilos Gram negativos em torneiras de um hospital de Volta Redonda-RJ, mui- 
tos microrganismos podem sobreviver em condições muito adversas, sendo necessário apenas um local úmido para sobreviverem. Dentre estes, destacam-se P. aeruginosa com $3 \%$ de frequência. Os resultados da pesquisa condizem com os valores encontrados em nosso estudo $(5,4 \%)$ e apontam, como possível causa, a ineficácia da limpeza periódica das torneiras como forma de minimizar a presença de micro-organismos, falta de conhecimento e/ ou treinamento da população em relação à forma correta de lavagem das mãos e o fechamento das torneiras ${ }^{(22)}$.

É lícito afirmar que, em qualquer lugar ou superfície, pode-se encontrar a presença de micro-organismos. O que preocupa é exatamente a colonização deles, tornando-os fontes e coadjuvantes das infecções ${ }^{(23)}$.

Os resultados apresentados por nós nessa pesquisa têm o intuito de esclarecer a população a respeito da cadeia de contaminação, da necessidade do cuidado em não tocar a torneira após a lavagem das mãos, reforçando também a importância de substituir as peças que exigem que as pessoas segurem na parte da torneira que foi tocada com a mão antes de ser lavada.

\section{Conclusão}

Frente à análise dos resultados da presente pesquisa, conclui-se que as superfícies das torneiras com as quais os usuários entram em contato, apresentaram contaminação por bactérias. Vale ressaltar que estas bactérias podem ser predominantemente da microbiota da pele e outras com potencial patogênico como $S$. aureus e Pseudomonas.

O fato pode ser devido à inexistência de um protocolo de limpeza das mesmas, falta de informação da população sobre a maneira correta de lavagem das mãos e utilização das torneiras após o uso dos banheiros, bem como o fato de as torneiras serem de uso manual.

O procedimento de lavagem das mãos perde sua eficácia, quando as mãos limpas tocam a torneira para fechá-la. Torneiras com fechamento automático são as mais indicadas para estes ambientes, pois evitam o contato manual para o fechamento das mesmas após a lavagem das mãos.

A maioria dos banheiros da instituição analisada não apresenta torneiras de fechamento automático. Como alternativa para o manuseio das torneiras de fechamento manual, sugere-se fechá-las segurando uma toalha de papel para que a mão limpa não entre em contato com a torneira ao fechá-la.

Os dados desta pesquisa devem ser divulgados para a comunidade da instituição, através do comitê de biossegurança, comunicação por artigo científico e publicação do artigo na revista Semente, visto que existe uma cadeia de contaminação iminente nas superfícies das torneiras desses banheiros.

\section{Referências}

1. Gerhardts A, Hammer TR, Balluff C, Mucha H, Hoefer D. A model of the transmission of micro-organisms in a public setting and its correlation to pathogen infection risks. J Appl Microbiol. 2012; 112(3):614-21.

2. Yildiz FH. Processes controlling the transmission of bacterial pathogens in the environment. Res Microbiol. 2007; 158(3):195202.

3. Scott E, Bloomfield SF. The survival and transfer of microbial contamination via cloths, hands and utensils. J Appl Bacteriol. 1990; 68(3):271-8.

4. Weber DJ, Anderson D, Rutala WA. The role of the surface environment in healthcare-associated infections. Curr Opin Infect Dis. 2013; 26(4):338-44.

5. Ferreira AM. Identificação de Staphylococcus aureus e Escherichia coli em superfícies e detecção de agentes contaminantes do ar em uma unidade de saúde, Belém-Pará. Trabalho de Conclusão de Curso. (Monografia). Belém (PA): Faculdade de Biomedicina da Universidade Federal do Pará; 2009.

6. Driscoll JA, Brody SL, Kollef MH. The epidemiology, pathogenesis and treatment of Pseudomonas aeruginosa infections. Drugs. 2007; 67(3):351-68.

7. Murray TS, Egan M, Kazmierczak BI. Pseudomonas aeruginosa chronic colonization in cystic fibrosis patients. Curr Opin Pediatr. 2007; 19(1):83-8.

8. Oie S, Hosokawa I, Kamiya A. Contamination of room door handles bymethicillin sensitive/methicillin-resistant Staphylococcus aureus. J Hosp Infect. 2002; 51(2):140-3.

9. Tenover FC, Hughes JM. The challenges of emerging infectious diseases: development and spread of multiply-resistant bacterial pathogens. JAMA. 1996; 275(4):300-4.

10. Keim LS. Mapeamento dos Estafilococos coagulase negativo no hospital Universitário Antônio Pedro da Universidade Federal Fluminense, no período de 1998 a 2002. Dissertação (Mestrado) Niterói: Universidade Federal Fluminense; 2005.

11. Custódio J, Alves JF, Silva FM, Dolinger EJOV, Santos JGS, Brito DVD. Avaliação microbiológica das mãos de profissionais da saúde de um hospital particular de Itumbiara, Goiás. Rev Ciênc Méd. 2009; 18(1):7-11.

12. Cecchin F, Cecchin LC, Wuchryn MI, Santos EB, Jorge JH, Urban VM. Estudo do nível de contaminação das superfícies e materiais das clínicas odontológicas da UEPG. In: $18^{\text {a }}$ EAIC [online]. 2009; Guarapuava. Anais. Guarapuava: 2009; Disponível em: http: / / www.eaic.uel.br/artigos/CD/3972.pdf (05 jul 2017)

13. Murray PR, Rosenthal KS, Pfaller MA. Microbiologia médica. 6a . ed. Rio de Janeiro: Guanabara Koogan; 2010.

14. Borges MF, Nassu RT, Pereira JL, Andrade APC, Kuaye AY. Perfil de contaminação por Staphylococcus e suas enterotoxinas e monitorização das condições de higiene em uma linha de produção de queijo de coalho. Ciênc Rural. 2008; 38(5):1431-8.

15. Holt J, Krieg N, Sneath P, Staley J, Willians S. Bergy's manual of determinative bacteriology. $9^{\text {th }}$ ed. Baltimore, MA: Williams and Willkins; 1994. 754p.

16. Jay JM, Loessner MJ, Golden DA. Indicators of food microbial quality and safety. In: Jay JM, Loessner MJ, Golden DA. Modern food microbiology. 7th ed. New York: Springer; 2005. p. 471-90.

17. Alves CFV, Santos RT, Lolli RR, Soares MCB. Condições higiênico-sanitárias de telefones públicos no município de Santos. Rev NewsLab. 2007; 82:192-200.

18. Pacheco Júnior FB, Sousa CF, Rocha TJM, Reys JRM, Rodrigues MML. Frequência de bactérias patogênicas nos computadores 
de uma instituição privada de ensino superior de Maceió - AL. BIOFAR. Rev Bras Biol Farm. 2011; 6(2):100-7.

19. Bonato BS, Castro FF, Carvalho TC, Gonçalves RHP, Martins CHG, Razaboni AM. Oculares de microscópios podem ser veículos de contaminação. NewsLab. 2007; 81:98-104.

20. Coutinho RL. Pseudomonas aeruginosa: a evolução da resistência aos antimicrobianos de uso terapêutico. 2008. Monografia (Curso de Especialização) Belo Horizonte: Instituto de Ciências Biológicas da UFMG; 2008.

21. Coelho Neto GT, Moraes FC, Monteiro Neto V, Figueirêdo PMS. Detecção de enterobactérias em superfícies de uma unidade Mista de saúde no município de São Luís, Maranhão, Brasil. Rev Invest Bioméd do Uniceuma. 2010; 1(2):77-84.
22. Pereira CAS, Alvarenga J, Barros AL, Silva AO. Pesquisa de bacilos gram negativos não fermentadores presente em torneiras de um hospital privado do município de Volta Redonda. Rev Epist Trans. 2012; 3(1):1-9.

23. Moreira LRC. Bancadas hospitalares: Superfícies e porosidades como fontes potenciais de infecção. Dissertação (Mestrado). São José dos Campos: Universidade do Vale Paraíba: Instituto de Pesquisa e Desenvolvimento; 2002.

Trabalho recebido: $25 / 09 / 2017$

Trabalho aprovado: 20/04/2018 